\title{
Influence of some factors on the production process of spring wheat plants
}

\author{
Nikolai Vasetsky ${ }^{1}$, Alexander Paramonov ${ }^{1 *}$, Oksana Tseluyko ${ }^{1}$, Andrey Fedyushkin ${ }^{1}$, and \\ Sergey Pasko ${ }^{1}$ \\ ${ }^{1}$ Federal State Budget Scientific Institution "The Federal Agrarian Scientific Centre of Rostov", 1, \\ Institutskaja Street, Rassvet, Aksay region, Rostovskaja oblast, 346735, Russia
}

\begin{abstract}
The article shows that the productivity of spring wheat is determined by the total effect of a set of conditions, each of which affects the amount of products obtained. As a result of the research, it was found that the yield of spring wheat directly depends on the hydrothermal conditions of the growing season. The key factor affecting the increase in the productivity of crops when using mineral fertilizers is the amount of precipitation during the growing season. The use of mineral fertilizers can significantly increase the yield of spring wheat, reducing the negative effect of the hydrothermal conditions of the growing season. So, when $\mathrm{N}_{60} \mathrm{P}_{30} \mathrm{~K}_{60}$ was introduced, the yield increase in different climatic conditions of the research years was $9,3 \ldots 92,8 \%$. It was also found that the reproductive function of durum spring wheat is characterized by the fact that the total number of caryopses of a shoot spike and their total weight are in close proportional dependence on the value of its vegetative mass. In this case, the value of the grain-straw ratio is a consequence of the proportional dependence of the reproductive elements of the shoot (acceptors) of wheat on the size of its vegetative (donors) organs.
\end{abstract}

\section{Introduction}

Spring wheat is a widely cultivated crop in the world, therefore, scientific research devoted to the issues of obtaining stable yields of this crop is carried out in many countries [1-10]. Wheat yield is formed under the influence of a complex set of conditions, each of which affects its quantity and quality. In the future, due to global warming, the importance of temperature and water regimes will grow [11-14]. Analysis of the elements of the crop, which determine its size and quality, makes it possible to more fully reveal the interaction between wheat plants and the environment in different periods of the growing season and, on this basis, draw up a cultivation technology taking into account the soil and climatic conditions of the region.

One of the indicators allowing to determine the supply of plants with moisture is the hydrothermal coefficient [15]. The ratio of the weight of a plant grain to its aboveground vegetative mass is a specific indicator. It expresses the measure in which a unit of

\footnotetext{
* Corresponding author: alexandr191914@mail.ru
} 
vegetative mass produces grain. The higher the numerical value of the indicator, the higher the individual plant productivity.

Therefore, studies on the influence of the hydrothermal coefficient on the yield and on the reproductive function of the shoot from the standpoint of the donor-acceptor relations of its reproductive and vegetative organs, which underlie the biology of a cereal plant and determine the level of its productivity, are currently isolated and relevant.

\section{Materials and methods}

The studies were carried out in the Aksai district of the Rostov region on the experimental field of the Federal Scientific Rostov Agrarian Center. The object of research is spring wheat. The soil of the experimental site is represented by ordinary chernozem, the granulometric composition is heavy loamy, in places light loamy. The thickness of the humus horizon is $75-100 \mathrm{~cm}$, the humus content is $3,6-4,0 \%$. The content of gross nitrogen $-0,22-0,24$, total phosphorus $-0,17-0,18$, potassium $-2,3-2,4 \%$, mineral nitrogen and mobile phosphorus - low, exchangeable potassium - increased. The climate of the zone is continental, moderately hot. The annual air temperature averages $9,6^{\circ} \mathrm{C}$, the sum of temperatures is $3200-3400^{\circ}$. The duration of the warm period is $230-260$ days, the frost-free period is $175-180$ days. The average annual precipitation is $500 \mathrm{~mm}$, during the warm period, it falls up to $300 \mathrm{~mm}$.

Fertilization scheme: I - control (without fertilizers) II - $\mathrm{N}_{60}$, III - $\mathrm{P}_{30}$, IV - $\mathrm{K}_{30}, \mathrm{~V}$ $\mathrm{N}_{60} \mathrm{P}_{30}$, VI - $\mathrm{N}_{30}$, VII - $\mathrm{N}_{60} \mathrm{~K}_{60}$, VIII - $\mathrm{P}_{30} \mathrm{~K}_{60}$, IX $-\mathrm{N}_{60} \mathrm{P}_{30} \mathrm{~K}_{60}$. Phosphate fertilizers and potassium - $\mathrm{KCl}(60 \%)$ were applied for the main treatment, nitrogen fertilizers - for the main one and for top dressing in the form of ammonium nitrate $(34,5 \%)$ in the tillering and tube emergence phase. The setting of experiments, accounting and mathematical processing of the data obtained were carried out according to B.A. Dospekhov. Agrotechnics are generally accepted for the zone. The method of placing plots is systematic. The repetition is threefold. The calculation of the hydrothermal coefficient was carried out according to G.T. Selyaninov. The selection of sheaves and their analysis were carried out according to the generally accepted methodology in crop production. The method of systemic morphogenetic study of wheat plants based on the species of the VIR collection was developed and published.

\section{Results}

The Rostov region belongs to the zone of unstable moisture, which makes the amount of precipitation a factor that determines the yield of any agricultural crop. One of the indicators allowing to determine the supply of plants with moisture is the hydrothermal coefficient.

Analysis of the hydrothermal coefficient of the growing season of spring wheat from 2007 to 2018 showed that the growing season of 2007, 2013 and 2018 (Fig. 1) characterized as dry, 2009 - very dry, two years 2008 and 2012 were arid, four were slightly arid (2010, 2014, 2016 and 2018). In dry years, the amount of precipitation that fell during the growing season of the studied crop did not exceed $60 \mathrm{~mm}$, and the value of the HTC ranged from 0,19 to $0,31.2011$ and 2015 were characterized by the highest moisture supply. During the growing season of spring wheat, 240,5-248,0 $\mathrm{mm}$ of atmospheric precipitation fell, while the sum of effective temperatures ranged from 1590 to $1749{ }^{\circ} \mathrm{C}$, and the GTC was in the range of 1,38-1,56. 


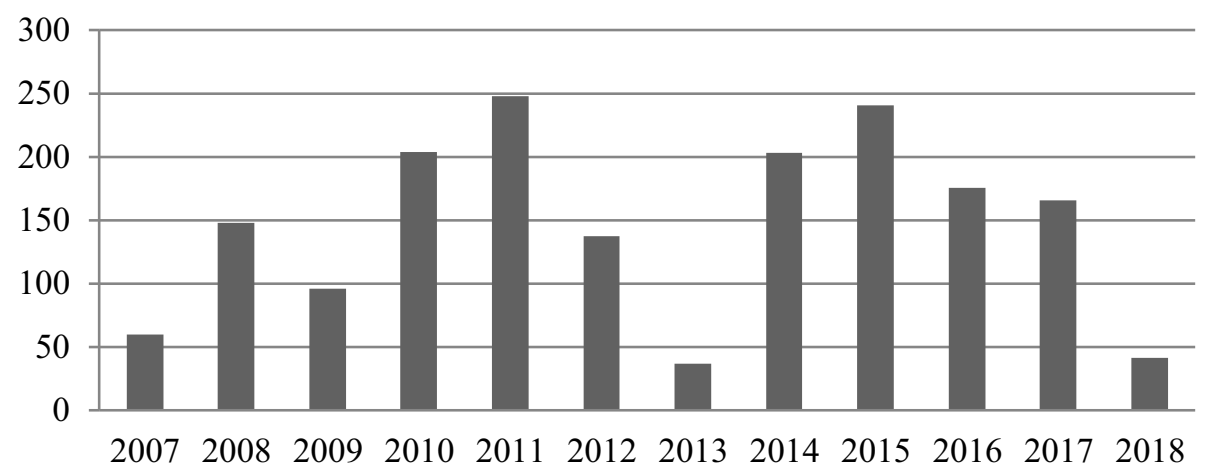

- Amount of precipitation, $\mathrm{mm}$
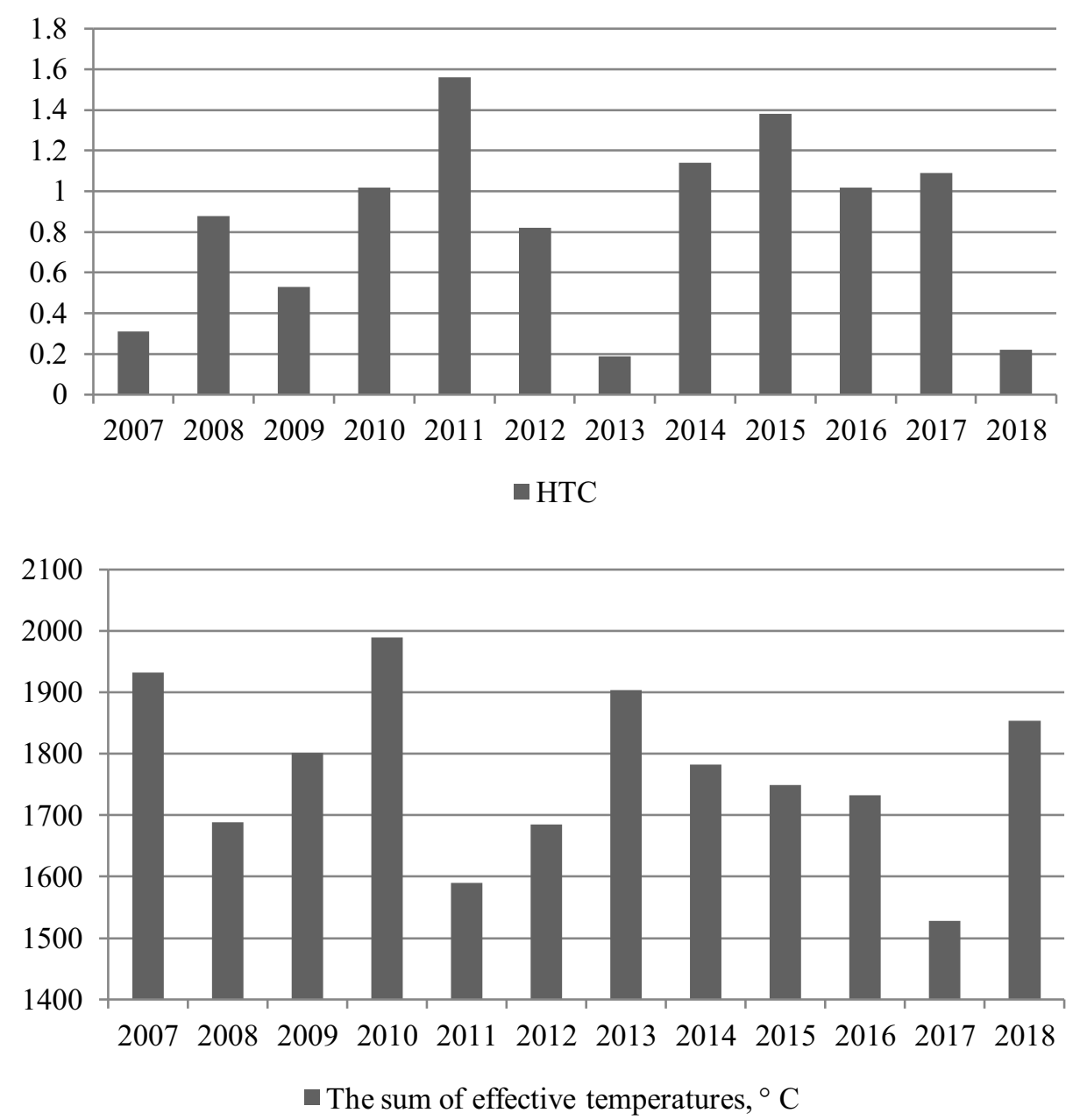

Fig. 1. Hydrothermal indicators of the growing periods of spring wheat during the years of research. 
The most accurate indicator characterizing the effectiveness of the use of one or another agricultural technique is the yield of the cultivated crop. During the research period, the introduction of mineral fertilizers significantly increased the yield of spring wheat (Table $1)$.

Table 1. Yield of spring wheat, $\mathrm{kg} / \mathrm{ha}$.

\begin{tabular}{|c|c|c|c|c|c|c|c|c|c|c|c|c|}
\hline \multirow{2}{*}{ Option } & \multicolumn{10}{|c|}{ Research year } \\
\cline { 2 - 14 } & 2007 & 2008 & 2009 & 2010 & 2011 & 2012 & 2013 & 2014 & 2015 & 2016 & 2017 & 2018 \\
\hline $\begin{array}{c}\text { The } \\
\text { control }\end{array}$ & 15,1 & 24,8 & 18,6 & 18,6 & 25,0 & 15,3 & 11,1 & 17,6 & 23,6 & 24,1 & 16,9 & 16,2 \\
\hline $\mathrm{N}_{60}$ & 18,3 & 27,7 & 24,2 & 24,1 & 30,6 & 26,8 & 17,7 & 16,5 & 28,4 & 29,1 & 22,9 & 18,8 \\
\hline $\mathrm{P}_{30}$ & 17,8 & 28,0 & 23,6 & 23,6 & 28,9 & 23,1 & 18,0 & 17,6 & 26,4 & 27,6 & 19,1 & 18,5 \\
\hline $\mathrm{K}_{30}$ & 16,3 & 27,4 & 20,2 & 20,1 & 26,6 & 19,7 & 17,6 & 16,3 & 25,3 & 26,2 & 17,4 & 17,0 \\
\hline $\mathrm{N}_{60} \mathrm{P}_{30}$ & 17,6 & 22,2 & 24,0 & 24,1 & 33,7 & 26,5 & 18,5 & 17,3 & 32,2 & 33,4 & 25,4 & 20,3 \\
\hline $\mathrm{N}_{30}$ & 17,9 & 23,5 & 22,7 & 22,7 & 31,1 & 28,6 & 17,2 & 17,8 & 26,8 & 27,2 & 19,8 & 18,9 \\
\hline $\mathrm{N}_{60} \mathrm{~K}_{60}$ & 17,9 & 24,6 & 23,7 & 23,8 & 33,2 & 25,5 & 17,7 & 17,9 & 30,7 & 31,2 & 23,6 & 20,2 \\
\hline $\mathrm{P}_{30} \mathrm{~K}_{60}$ & 16,8 & $25,8,0$ & 22,0 & 22,0 & 28,6 & 23,3 & 18,5 & 16,2 & 29,6 & 30,1 & 21,8 & 18,2 \\
\hline $\mathrm{N}_{60} \mathrm{P}_{30} \mathrm{~K}_{60}$ & 18,3 & 27,1 & 27,9 & 27,9 & 35,1 & 35,0 & 21,4 & 27,7 & 34,7 & 35,8 & 29,6 & 21,9 \\
\hline $\mathrm{LSD}_{05}$ & 1,8 & 2,4 & 1,9 & 1,5 & 2,1 & 2,7 & 2,4 & 3,3 & 2,2 & 2,4 & 1,7 & 2,1 \\
\hline
\end{tabular}

The yield, depending on the application of fertilizers and the year of research of the studied crop, varied widely (from 11,1 to $35,8 \mathrm{c} / \mathrm{ha}$ ). The use of mineral fertilizers led to a significant increase in the yield of spring wheat, an increase with the introduction of $\mathrm{N}_{60} \mathrm{P}_{30} \mathrm{~K}_{60}$ made it possible to increase the yield by $9,3 \ldots 92,8 \%$.

The calculation of the multiple correlation coefficient showed that in the non-fertilized version, there is a direct average relationship between the yield of spring wheat, the amount of precipitation and the SCC, and there is a weak inverse relationship between the amount of active temperatures (Table 2).

Table 2. Correlation coefficients ( $r$ ) of spring wheat yield and hydrothermal parameters of the growing season.

\begin{tabular}{|c|c|c|c|c|c|c|c|c|}
\hline \multirow{2}{*}{ Indicators } & \multicolumn{9}{|c|}{ Option } & $\begin{array}{c}\text { The } \\
\text { contr } \\
\text { ol }\end{array}$ & $\mathrm{N}_{60}$ & $\mathrm{P}_{30}$ & $\mathrm{~K}_{60}$ & $\mathrm{~N}_{60} \mathrm{P}_{30}$ & $\mathrm{~N}_{60} \mathrm{~K}_{60}$ & $\mathrm{P}_{30} \mathrm{~K}_{60}$ & $\mathrm{~N}_{60} \mathrm{P}_{30} \mathrm{~K}_{60}$ \\
\hline $\begin{array}{c}\text { Amount of } \\
\text { precipitation, } \\
\text { mm }\end{array}$ & 0,63 & 0,82 & 0,80 & 0,80 & 0,82 & 0,86 & 0,85 & 0,81 \\
\hline $\begin{array}{c}\text { The sum of } \\
\text { active } \\
\text { temperatures, } \\
{ }^{\circ} \mathrm{C}\end{array}$ & $-0,37$ & $-0,60$ & $-0,42$ & $-0,42$ & $-0,55$ & $-0,58$ & $-0,53$ & $-0,63$ \\
\hline HTC & 0,64 & 0,84 & 0,79 & 0,79 & 0,84 & 0,88 & 0,86 & 0,84 \\
\hline
\end{tabular}

The use of mineral fertilizers led not only to an increase in the yield of spring wheat, but also to an increase in the dependence of this indicator on the meteorological conditions of the growing season. So, on the variant with the use of fertilizers at a dose of $\mathrm{N}_{60} \mathrm{P}_{30} \mathrm{~K}_{60}$, a close direct relationship was observed between the yield, the SCC and the amount of precipitation $(\mathrm{r}=0,81)$, while the relationship between the yield and the sum of active temperatures was inverse and average in effect $(r=-0,63)$.

Thus, the yield directly depended on the hydrothermal conditions of the growing season, and the key factor affecting the increase in crop productivity when using mineral fertilizers was the amount of precipitation during the growing season. 
Differences in the hydrothermal parameters of the growing season had a significant effect on the yield of spring wheat, both in the control and in the variants with the use of mineral fertilizers. So, in the years with the poorest moisture supply (HTC up to 0,4 ), the yield of the studied crop in the control variant averaged $14,8 \mathrm{c} /$ ha. With the growth of the hydrothermal coefficient, the yield increased. In the years with the GTC equal to 0,7-1,0, this indicator averaged $20,1 \mathrm{c} /$ ha, and in the wettest years $-24,3 \mathrm{c} /$ ha. A similar trend was noted for the variants with the use of mineral fertilizers.

Even with a critically low amount of precipitation of spring wheat during the growing season, which does not allow plants to efficiently use nutrients from the applied fertilizers, i.e. in years with HTC equal to 0,19 ... 0,31 (2007, 2013 and 2018), significant differences were noted in the effectiveness of the use of complete mineral fertilizer at a dose of $\mathrm{N}_{60} \mathrm{P}_{30} \mathrm{~K}_{60}$.

Since there is a direct strong relationship between the yield, hydrothermal coefficient (HTC) and the amount of precipitation in the fertilized variants, a regression analysis of these values was carried out. The plots constructed according to the regression equation between the two variables show that the increase in yield by applying $\mathrm{N}_{60}$ by $71,9 \%$ depends on the value of the hydrothermal coefficient (Fig. 2). The influence of the amount of precipitation was $68,6 \%$.

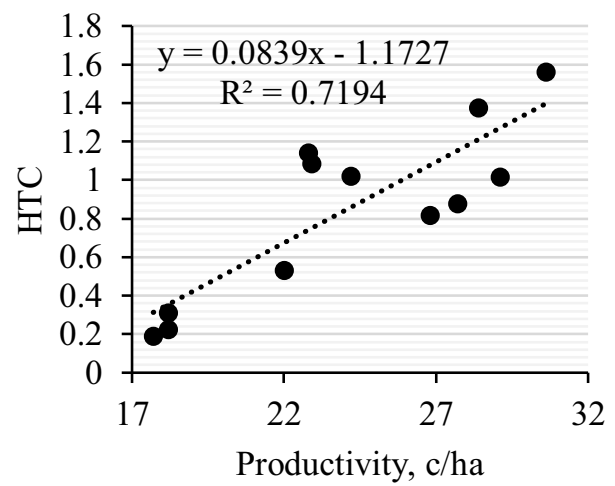

a)

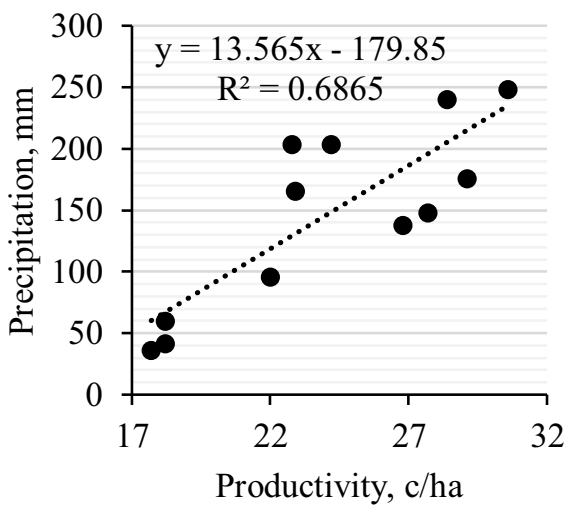

b)

Fig. 2. Dependence of the yield of spring wheat on the HTC (a) and the amount of precipitation during the growing season (b) (option N60).

With the combined use of nitrogen and potash fertilizers in a dose of $60 \mathrm{~kg}$ of active ingredient, the dependence of yield on the hydrothermal coefficient increased to $71,3 \%$, and on the amount of precipitation up to $67,4 \%$ (Fig. 3). 


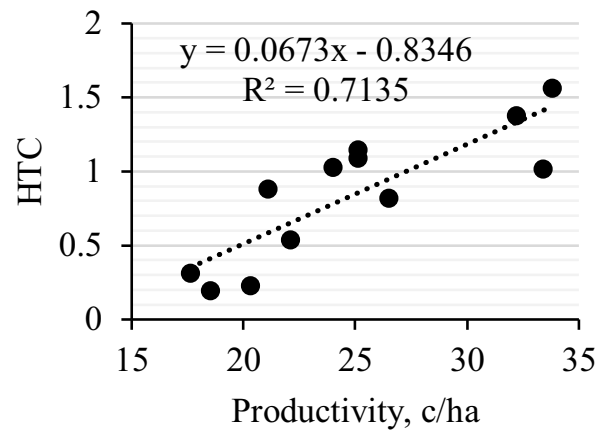

a)

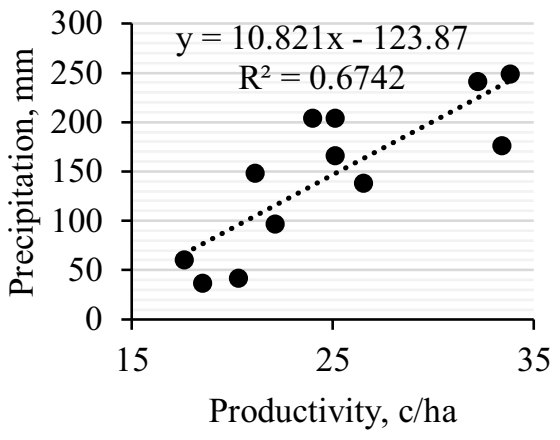

b)

Fig. 3. Dependence of the yield of spring wheat on the HTC (a) and the amount of precipitation during the growing season (b) (option $\mathrm{N}_{60} \mathrm{~K}_{60}$ ).

With the combined use of nitrogen and phosphorus fertilizers at a dose of $\mathrm{N}_{60} \mathrm{P}_{30}$, the above indicators increased to $77,4 \%$ and $73,5 \%$, respectively (Fig. 4).

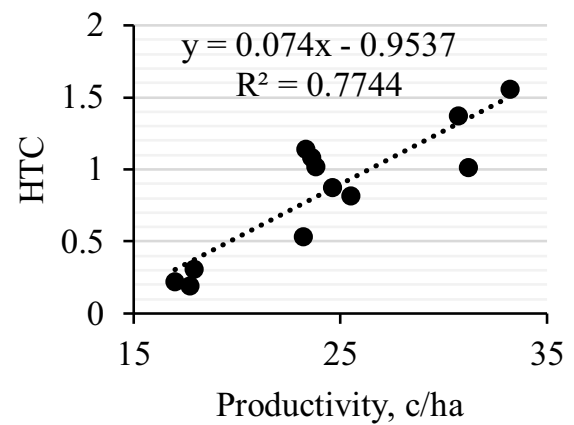

a)

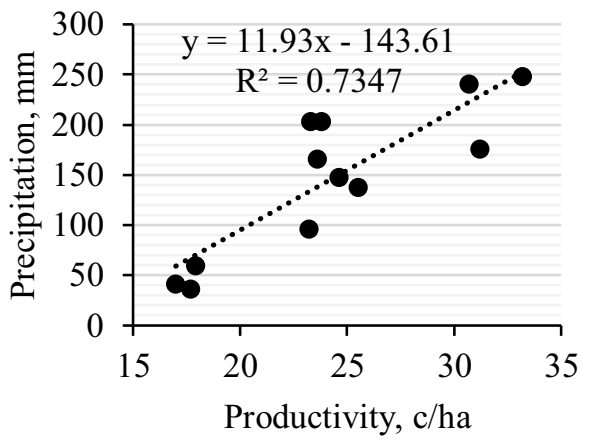

b)

Fig. 4. Dependence of the yield of spring wheat on the HTC (a) and the amount of precipitation (b) during the growing season (option $\mathrm{N}_{60} \mathrm{P}_{30}$ ).

With the introduction of full mineral fertilizer at a dose of $\mathrm{N}_{60} \mathrm{P}_{30} \mathrm{~K}_{60}$, the influence of the hydrothermal coefficient and precipitation on the yield decreased, amounting to 69,8 and $65,7 \%$, respectively (Fig. 5). This effect was presumably associated with a more efficient water consumption by wheat plants when using a complete mineral fertilizer, which made it possible to reduce the consumption of productive moisture for the formation of a crop unit. 


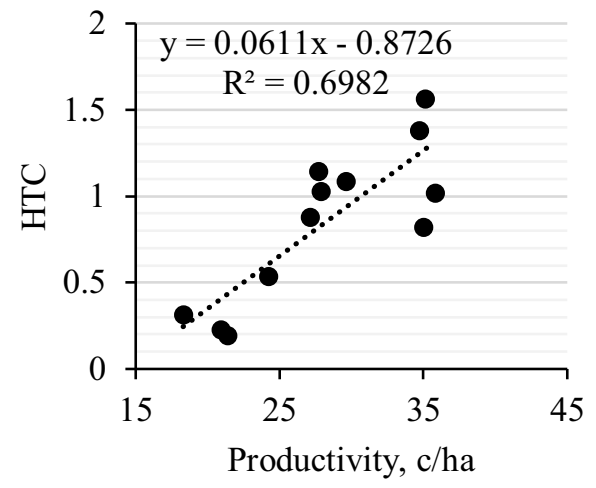

a)

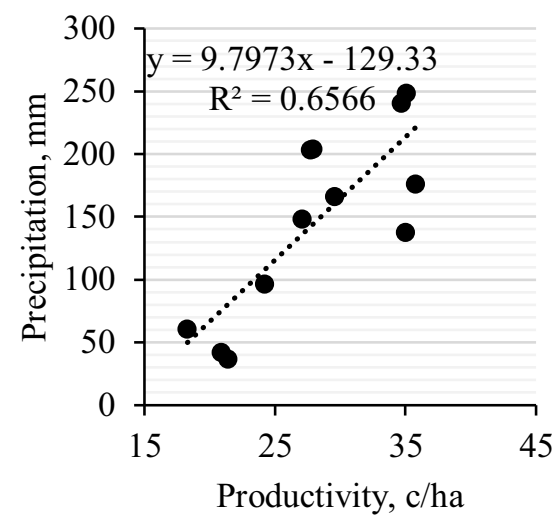

b)

Fig. 5. Dependence of the yield of spring wheat on the HTC (a) and the amount of precipitation that fell during the growing season (b) when applying $\mathrm{N}_{60} \mathrm{P}_{30} \mathrm{~K}_{60}$.

The ratio of the weight of a plant grain to its aboveground vegetative mass is a specific indicator. It expresses the measure in which a unit of vegetative mass produces grain. The higher the numerical value of the indicator, the higher the individual plant productivity. The conducted studies of the reproductive function of wheat and their wild-growing ancestors by the vegetative method showed that the total number of caryopses of a spike and their total weight are in close proportional dependence on the value of the vegetative mass of the shoot. Subsequent studies have shown that when growing in natural conditions of the field, such a relationship also takes place in durum wheat plants in different years (Fig. 6, 7).
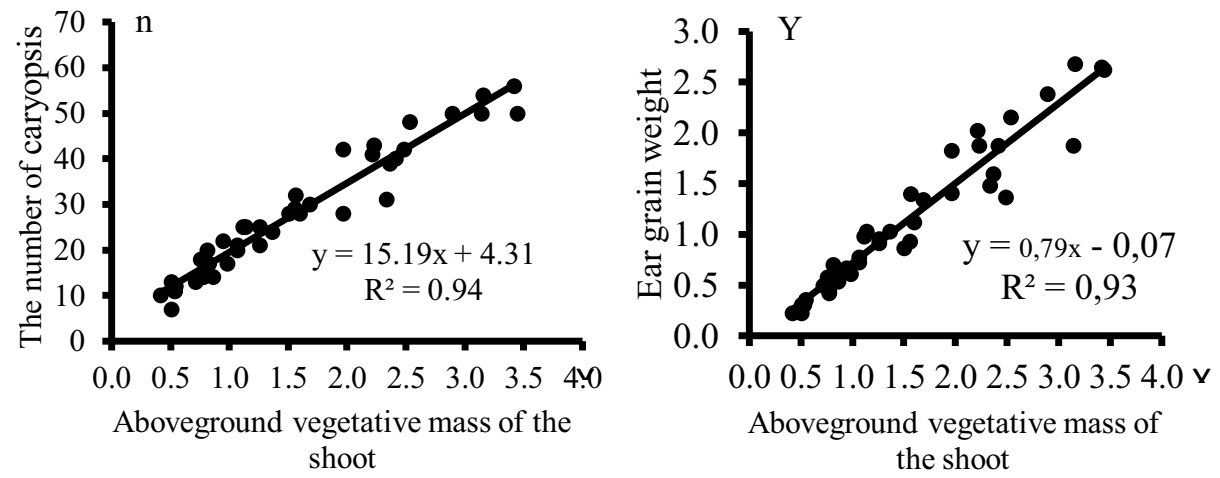

Fig. 6. Dependence of the total number of spike grains (n) and their total weight $(\mathrm{Y})$ on the vegetative (leaves, internodes, spikelet, spike, scales, awn) shoot mass (X) in durum spring wheat varieties in the full ripeness phase ... 2003 year. 


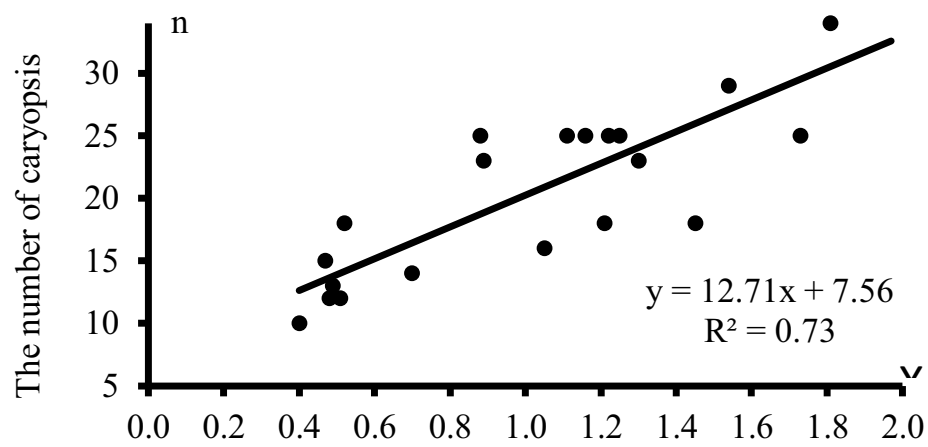

Aboveground vegetative mass of the shoot

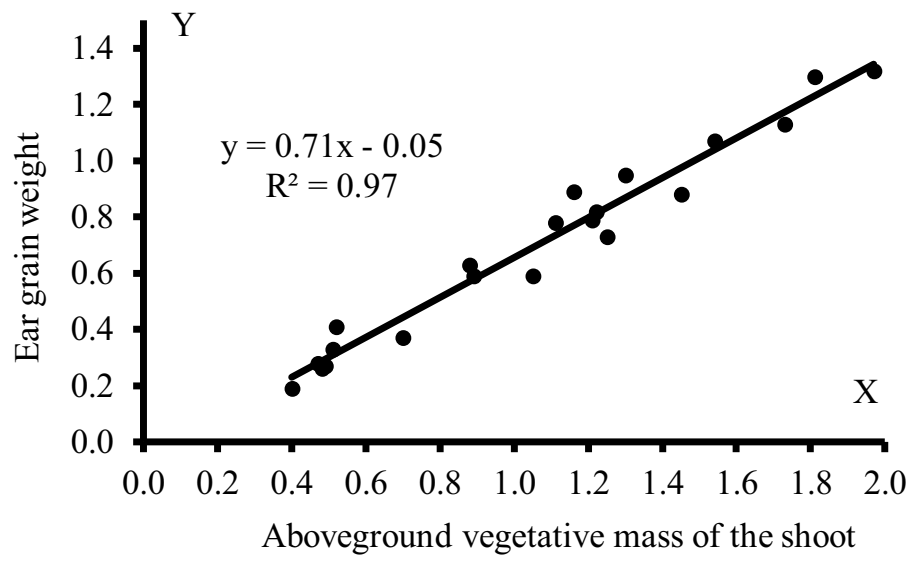

Fig. 7. Dependence of the total number of spike grains (n) and their total weight $(\mathrm{Y})$ on the vegetative (leaves, internodes, spikelet, spike, scales, awn) shoot mass (X) in durum spring wheat plants at full ripeness. 2009 year.

An analysis of three-year experimental data given in Table 3 shows that with different total weights of sheaves in the control variant and the variant with mineral fertilizer at a dose of $\mathrm{N}_{60} \mathrm{P}_{30} \mathrm{~K}_{60}$, the ratio of grain to straw in them really remains in a very narrow range of numerical values $(0,57-0,65)$.

Table 3. Ratio of grain-straw in spring durum wheat plants of the cultivar on the control and fertilized variants on ordinary chernozem according to the precursor of alfalfa, 2009-2011.

\begin{tabular}{|c|c|c|c|c|c|c|c|c|}
\hline \multirow{2}{*}{ Year } & \multicolumn{4}{|c|}{ The control } & \multicolumn{4}{c|}{$\mathrm{N}_{60} \mathrm{P}_{30} \mathrm{~K}_{60}$} \\
\cline { 2 - 9 } & $\begin{array}{c}\text { weight } \\
\text { sheaf, } \mathrm{g}\end{array}$ & $\begin{array}{c}\text { weight } \\
\text { grains, } \\
\mathrm{g}\end{array}$ & $\begin{array}{c}\text { weight } \\
\text { straw, } \mathrm{g}\end{array}$ & $\mathrm{g} / \mathrm{s}$ & $\begin{array}{c}\text { weight } \\
\text { sheaf, g }\end{array}$ & $\begin{array}{c}\text { weight } \\
\text { grains, } \mathrm{g}\end{array}$ & $\begin{array}{c}\text { weight } \\
\text { grains, } \\
\mathrm{g}\end{array}$ & $\mathrm{g} / \mathrm{s}$ \\
\hline 2009 & 65 & 25 & 40 & 0,62 & 76 & 30 & 46 & 0,65 \\
\hline 2010 & 55 & 20 & 35 & 0,57 & 88 & 33 & 55 & 0,60 \\
\hline 2011 & 51 & 20 & 31 & 0,64 & 84 & 31 & 53 & 0,58 \\
\hline
\end{tabular}

Note: $\mathrm{g} / \mathrm{s}$ is the ratio of grain mass to straw mass. 


\section{Conclusions}

The yield of spring wheat directly depends on the hydrothermal conditions of the growing season. The key factor affecting the increase in the productivity of crops when using mineral fertilizers is the amount of precipitation during the growing season.

The use of mineral fertilizers can significantly increase the yield of spring wheat, reducing the negative effect of the hydrothermal conditions of the growing season. With the introduction of a complete mineral fertilizer in a dose of $\mathrm{N}_{60} \mathrm{P}_{30} \mathrm{~K}_{60}$, the yield increase in different hydrothermal conditions of the research years was $9,3 \ldots 92,8 \%$.

In durum spring wheat of the variety, the reproductive function is characterized by the fact that the total number of caryopses of a shoot spike and their total weight are in close proportional dependence on the value of its vegetative mass. The grain-straw sheaf ratio reflects the proportional nature of the relationship between the reproductive and vegetative elements of the wheat shoot and is its natural consequence.

\section{References}

1. Q. Jing, B. McConkey, B. Qian, et al., Agricultural Water Management, 244, 106591 (2021), doi.org/10.1016/j.agwat.2020.106591

2. C. Yang, H. Fraga, W. van Ieperen, J. A. Santos, Agricultural Systems, 182, 102844 (2020), doi.org/10.1016/j.agsy.2020.102844

3. P. Khalili, M. B. Masud, B. Qian, S. Mezbahuddin, M. Dyck, M. Faramarzi, Science of The Total Environment, 145474 (2021), doi.org/10.1016/j.scitotenv.2021.145474

4. B. Wang, P. Feng, C. Waters, J. Cleverly, D. L. Liu, Q. Yu, Agricultural and Forest Meteorology, 291, 108043 (2020), doi.org/10.1016/j.agrformet.2020.108043

5. J. L/ Gouis, F.-X. Oury, G. Charmet, Journal of Cereal Science, 93, 102960 (2020), doi.org/10.1016/j.jcs.2020.102960

6. M. Mousavi-Baygi, M. Bannayan, B. Ashraf, E. AsadiOskuei, Ecological Indicators, 62, 298-305 (2016), doi.org/10.1016/j.ecolind.2015.11.007

7. Z. Dong, Z. Pan, Q. He, et al., Ecological Indicators, 85, 67-78 (2018), doi.org/10.1016/j.ecolind.2017.10.008

8. L.G. Muhamedyarova, M.A. Derkho, G.V. Meshcheriakova, et al., Agronomy Research, 18(2), 483-493 (2020), 10.15159/AR.20.152

9. B. Tuvdendorj, B. Wu, H. Zeng, et al., Remote Sensing, 11(21), 2568 (2019), $10.3390 / \mathrm{rs} 11212568$

10. C. Wang, L.-X. Wang, Q. Li, et al., Chinese Journal of Ecology, 38(7), 2049-2056, (2019)

11. D.I. Ivanov, N.N. Ivanova, A.D.R. Alhajemi, Ecology, Environment and Conservation, 26( 1), 400-404 (2020)

12. E.A. Babushkina, L.V. Belokopytova, D.F. Zhirnova, et al., International Journal of Biometeorology, 62(6), 939-948 (2018), 10.1007/s00484-017- 1496-9.

13. T. Karimi, C.O. Stoctle, S. Higgins, R. Nelson, Agricultural Systems, 159, 144-156 (2018) 10.1016/j.agsy.2017.03.014.

14. L. Cheng, R. Wang, J. Xu, et al., International Journal of Biometeorology, 62(12), 2197-2204 (2018), 10.1007/s00484- 018-1623-2

15. D.I. Ivanov, N.N. Ivanova, A.D.R. Alhajemi, Ecology, Environment and Conservation, 26(1), 400-404 (2020) 